\title{
Thinking about Applied talents Training Mode of Chinese Language and Literature Majors \\ Li Li $\mathbf{i}^{1, a}$
}

\author{
${ }^{1}$ School of National Education, Nanchang Institute of science \& Technology, Nanchang 330108 , \\ China; \\ a'zhuxiazju@163.com
}

Keywords: Chinese Language and Literature Majors, Applied, Talents Training Mode.

\begin{abstract}
With the popularization of higher education in recent years, talents mode of undergraduate education has been transformed from outstanding person to popular education. The applied talents training mode of Chinese language and literature majors have become a crucial question. After analyzing the existing the problem of applied talents training mode of Chinese language and literature majors of china's high, the implementation from applied talents training mode of Chinese language and literature majors have been put forward on the orientation of talent cultivation, curriculum structure optimization, the reform of teaching and emphasizing practicing teaching.
\end{abstract}

\section{Introduction}

Being affected by rapid development of economic and deepening educational structural-reform, traditional training mode of Chinese language and literature majors are not fit for present higher education development requirement. The graduate employment situation is very sever, Chinese language and literature students cannot be optimistic about the employment situation. Chinese language and literature, as a traditional humanities courses, it is opened in the major colleges and universities across the country. Research on how to demonstrate discipline advantages in subject competition is a worth thoroughly pondering. The author thinks that the applied talents training are a major trend of development of local colleges and universities. However, there are some problems of the existing applied talents training mode of Chinese language and literature, we need to continue to study and find a better flow of the market on the road, to adapt to the new century.

\section{The Existing Problem of Talents Training of Chinese Language and Literature Majors Mode in Higher Education.}

Training Goal is Unclear. Chinese language and literature majors had once a brilliant period of development. Back then, students of Chinese language and literature majors had felt pride and a sense of superiority, and had a steady and satisfactory job. However, with the popularization of higher education, the Chinese language and literature majors of local higher colleges will lose advantages of original majors and cultural status. These problems will influence students' employment. With the rapid development of society, the demanding for Chinese language and literature talents are changing. However, the training goals of many colleges are not adjusted timely. They refused to consider actual needs of the job market and overemphasize the professional education. These practices don't allow students' knowledge to broaden, and make students much less confident of Chinese language and literature major.

The Unreasonable Curriculum Structure. (1) The setting of professional color is too strong in most colleges. Unlike other applied subjects, Chinese language and literature majors have their own particularity. Only a small percentage student chooses to continue their professional pursuits, most students choose to leave. In addition, the specialized knowledge rarely has been covered by the actual work. The establishment of Chinese language and literature majors overemphasizes professional color in many colleges. This attitude is good for talents training, but it is not good for abilities training 
of students. In addition, it will crap students' views, and is not good for students' development in very profession.

(2) The content of course lacks age characteristics. For pursuing excessively application, there are some problems in talent training of Chinese language and literature majors, such as repeated teaching contents, lag of courses plan, etc. Course content is concrete steps of achieving the aim of teaching and concrete realization of teaching plans. The author thinks that the curriculum should meet the scientific, reasonable and feasible characteristics.

Lacking of Regard for Teaching Practice. Chinese language and literature majors has emphasized in teaching of professional knowledge, neglected the training of students' abilities. Some teachers cannot change the traditional teaching method, and lacks understanding of practice teaching. Some teachers pay less attention to practice teaching. The attitude cannot simulate students' activeness, and results in ineffective teaching outcome. Again, teaching processing cannot meet the requirement of applied talents.

\section{The Right Location of Talents Training.}

Implementing Transition of Training Goal toward diversify. Because the confusion among department and industries has become more and more chose in current society, the pure language worker cannot meet the requirement of market. Therefore, we should study talents training goal, and implement repositioning. According to requirement of different industries, we should establish a talents training mode with own characteristics. For example, according to market requirement, the specialized course should be divided into different modules. Students can choose fit courses to learn in accordance with their own interests.

Implementing Transition of Training Goal toward Internationalization. Because the influence of Chinese and Chinese culture has become more and more prominent, Chinese language and literature are sure to be rewarded with broader space of development, and go international. Meanwhile, requirement of Chinese language and literature talents become higher. Students of Chinese language and literature majors should master bilingualism. In the globalized world today, if Chinese language and literature talents master profound basis and at least one foreign language, then they will be welcomed by the market. So it is an essential requirement for course teaching. This would make the talents with bilingualism more welcomed.

Implementing Transition of Training Goal toward Modernization. In the pattern of traditional education, Chinese language and literature talents only understand their textbook knowledge and skilfully apply language and literature. They lack familiarity with the modern information technology and don't keep up with the times, so they cannot meet the need of the modern society. The modern talents of Chinese language and literature should not only master Chinese and foreign language, but also fully understand the modern information technology. That is to say, they should not only possess solid specialized knowledge and skill, but also master some editing and manufacturing technology. So some skill courses should be added in teaching of Chinese language and literature majors.

\section{Optimizing the Curriculum Structure.}

Optimizing the Specialized Elementary Curriculum. The major basic courses include ancient Chinese language, modern Chinese language, Chinese ancient literacy and Chinese contemporary literature. The aim of the major basic courses is the cultivation of students' major theory quality. In general, the whole framework of the major basic courses doesn't need to be changed radically, but the course content need to be adjusted. The operating methods include the following:

(1) Reducing the teaching content. Teachers should design the course system and teaching contents in accordance with the new knowledge structure, and confirm teaching content, teaching important point and difficult point. 
(2) Optimizing the course structure. It is necessary to combine the academic knowledge with the direction of current academic development. Consequently, it is able to make the possible use of the course's teaching effect.

(3) Integrating the course content. The present Chinese language and literature share the problems of unreasonable structure and repeated teaching contents. The author think teaching contents of Chinese language and literature should be integrated.

Refining Major Field. In order to broaden the application of Chinese language and literature, the major field of Chinese language and literature can be divided into three directions: normal, foreign-related secretary and culture industry management. The junior students can take the elective courses as major field, so as to train the professional fundamental abilities. The senior students must take the elective courses as major field, so as to train the professional abilities. In addition, teachers should encourage students to take free elective courses, so as to train the students' abilities in various aspects.

\section{Reforming Teaching Method.}

Constructing the Basic Knowledge of Majors. Because junior students are just starting to make the major, there is no systematic and coherent cognitive framework. So when teachers teach basic specialized knowledge to students, teachers should teach the theory framework of the major courses to junior students. Practice shows that it is impractical to implement prematurely exploring experimental teaching. It cannot achieve the effect of training students' self-study abilities. Students' first year at college is on the foundation. Teachers should apply cognitive studying theory to teaching processing, so as to help students set up a systematic knowledge framework.

Implementing Probing Teaching Method. Though college sophomore have study the specialized fundamental courses, their theory ability level have been improved. Then teaching method should be transformed from systematic teaching to probing teaching method. The so-called probing teaching method is that students found and explore actively some problems, and find the methods to these problems with the help of the teacher, so as to enhance students' power of observation and train students' spirit of innovation. In probing teaching method processing, teachers play a leading role and students are a main body.

Taking Teaching Method of Instructional Activities. The senior students should actively choose some option courses and applied skill courses. Teacher should implement teaching processing by using the constructivism teaching method. Students form a good habit of learning actively and their own views with the help of the teachers. The teaching method makes students' professional applied abilities get the promotion. Teachers will take much time and energy. So the teaching evaluation method and computing methods will need to be adjusted.

\section{Strengthening Practice Teaching Link.}

According to the requirement of different orientation of Chinese language and literature, the practice processing of the applied talents include some teaching practice activities, such as extracurricular activities, specialized practice, practice teaching and educational practice.

Making Extra-curricular Activities. The innovation capacity of students has a stake in the colleges' attention. Colleges and universities should pay attention to developing students' innovation, and formulate related policies, so as to encourage and support students' innovation. In addition, some related departments should make some policies, so as to encourage students to take part in the research of their teachers, simulate students to publish paper, and organize students to take part in competition activities. As the same time, colleges and universities should construct the reward system, so as to simulate students' initiatives.

Implementing Timely Major Practice. According to teaching contents, colleges and universities should organize students to take part in the practice. The professional practice can not only make 
students deepen understanding and memory of the theory knowledge, but also enhance the understanding and feeling of the related industries. It can improve the students' abilities to solve problems and enhance their enterprise, so as to lay the foundation for professional practice. However, a residency should not last long.

Carrying on Teaching Practice. The teaching practice of normal-based orientation of Chinese language and literature is arranged in the first semester of his senior year. Practice time have six weeks. The teaching object is the middle school students in the Practice, and the practice contents are teaching practice and teacher practice. Students will apply the professional knowledge to teaching practice, and take their applied skills to teaching practice. The teaching practice can make students apply book knowledge to practice, which can not only improve professional applying abilities, but also make a good foundation for students' aftertime works.

Arranging Majors Practice. Unlike the normal orientation, the professional practice of the advanced secretary and culture industry management are usually arranged in senior year. Some cultural units and the office need relatively few interns. In addition, practice place are geographically scattered, which is convenient to guide students. According to the requirements of present probation, the probation has tried practice to employment situation, which make students' internship become a special form of professional practice. In the process of students' internship, their performance will have an important influence on their future career, and their applied abilities will also make the decision to their remove or retain. Though the students' internship has some advantages, it also has some disadvantages. Therefore the employers should design the practice standard in accordance with the different requirement and professional orientation. In addition, colleges and universities should also strengthen the effective communication with the employer.

\section{Summary}

In a word, reformation of Chinese language and literature is a systematic engineering. This paper analyzes existing problems of Chinese language and literature talents training, and put forward some solving methods, such as the orientation of talent cultivation, curriculum structure optimization, the reform of teaching and emphasizing practicing teaching, etc. If implemented, the teaching mode $t$ will likely to transform from outstanding education to the popular in the Chinese language and literature teaching.

\section{References}

[1] F.Q.LI. Talking About School-running Mode of the Open Education, Distance Education in China, 12(2010):12-16.

[2] S.R.CHEN. On the Basic Ideas of the Applied Talents Training of Chinese Language and Literature Specialty, Journal of Juamjusi Education Institute, 2(2013):278-281.

[3] R.Q.ZHAI. Reflection on the Construction of the Application-orientated Talents Training Model of Chinese Language and Literature Specialty, Journal of Qilu Normal University, 30(2015):1-5.

[4] C.X.LIU, X.S.PAN. Thinking of the Application-orientated Talents Training Model of Chinese Language and Literature Specialty, Journal of Jinan Vocational College, 04(2012):25-26.

[5] W.J.QU. Practice and Exploration on Innovation Courses Construction of Chinese Language and Literature Specialty, Journal of Linyi University, 02(2010):33-36.

[6] Y.L.SUN. Study on Teaching Mode of Applied Talents of Chinese Language and Literature Specialty, 01(2014):05-06. 